\title{
Lipoma of the Neck
}

\author{
Ivanka Temelkova ${ }^{1}$, Uwe Wollina ${ }^{2}$, Veronica Di Nardo ${ }^{3}$, Georgi Tchernev ${ }^{4,55^{*}}$
}

${ }^{1}$ Medical Institute of the Ministry of Interior, Dermatology, Venereology and Dermatologic Surgery, Sofia, Bulgaria; ${ }^{2}$ Städtisches Klinikum Dresden, Department of Dermatology and Allergology, Academic Friedrichstrasse 41, Dresden, Germany; ${ }^{3}$ Department of Nuclear, Subnuclear and Radiation Physics, University of Rome "G. Marconi" via Plinio 44, Rome, Italy; ${ }^{4}$ Medical Institute of Ministry of Interior (MVR), Department of Dermatology, Venereology and Dermatologic Surgery General Skobelev Nr 79, Sofia, Bulgaria; ${ }^{5}$ Onkoderma-Policlinic for Dermatology and Dermatologic Surgery General Skobelev 26, Sofia, Bulgaria \begin{abstract}
Citation: Temelkova I, Wollina U, Di Nardo V, Tchernev
G. Lipoma of the Neck. Open Access Maced J Med Sci. G. Lipoma of the Neck. Open Access Maced J Med Sci
$2018 \quad$ Oct $25 ;(10): 1875-1877$
https://doi.org/10.3889/oamjms.2018.430

Keywords: Lipoma; Surgery; Conservative approach; MRI; Outcome

*Correspondence: Georgi Tchernev. Medical Institute of Ministry of Interior (MVR), Department of Dermatology, Venereology and Dermatologic Surgery General Skobele
$\mathrm{Nr}$ 79, Sofia, Bulgaria; Onkoderma-Policlinic Dermatology and Dermatologic Surgery General Skobelev 26, Sofia, Bulgaria. E-mail: georgi_tchernev@yahoo.de Received: 10-Sep-2018; Revised: 19-Oct-2018; Accepted: 21-Oct-2018; Online first: 23-Oct-2018

Copyright: ๑ 2018 Ivanka Temelkova, Uwe Wollina, Veronica Di Nardo, Georgi Tchernev. This is an openCommons Attribution-NonCommercial 4.0 international License (CC BY-NC 4.0)

Funding: This research did not receive any financial support

Competing Interests: The authors have declared that no Competing Interests: The
competing interests exist
\end{abstract}

\begin{abstract}
BACKGROUND: Lipomas are benign formations with the mesenchymal origin, which are found in the head and neck region in a very small percentage of cases. In these cases, they usually occur in the posterior neck and usually grow very slowly without causing complaints. However, when they cover the front of the neck, it is necessary to confirm the adipose origin of a tumour and to exclude the connection with the thyroid gland. Although in principle, lipomas are benign, there are three more unfavourable possibilities of 1) malignancy of lipomas, 2) the occurrence of de novo liposarcomas or 3) the association of lipomas with other tumours, such as retinoblastoma.
\end{abstract}

CASE REPORT: We present a 74-year-old woman with a painless subcutaneous formation in the neck. A Fine Needle Aspiration Biopsy (FNA) was performed, with the conclusion of the cytological result for lipoma. Surgical removal was planned under general anaesthesia.

CONCLUSION: Usually, lipomas do not require surgery, but when they engage muscles they become indicative of surgical treatment.

\section{Introduction}

Lipomas are benign tumours that are usually found in the subcutaneous tissue and can cover different parts of the body [1] [2]. They usually have a benign flowing course, but in rare cases, it is also possible to see a malignant transformation of the lipomas [3]. On the other hand, in some forms of lipomas, such as dysplastic lipomas, there is a possibility of an association between lipoma and another tumour, for example, retinoblastoma [4]. Although in most cases they are painless and slowgrowing, sometimes lipomas can grow significantly and infiltrate musculature, leading to symptomatology and to be an indication of surgical treatment [5] [6].

\section{Case report}

A 74-year-old woman was hospitalised due to a subcutaneous painless tumour formation of the ventral neck (Figures 1a and 1b). Ten years ago, the patient developed a "nodule" in the area of the thyroid gland that gradually increased by size and was now the reason for diagnostics to clarifying its nature. The patient's medical history was remarkable for arterial hypertension treated with amlodipine $5 \mathrm{mg}(0-0-1)$ and losartan potassium $50 \mathrm{mg}$ (1-0-0), osteoporosis treated with denosumab $60 \mathrm{mg} / \mathrm{ml} \times 1 /$ day for 6 months, as well as chronic venous insufficiency. Additionally, we noted itchy, disseminated nummular partially pyodermic patches, located on the face, trunk 
and extremities suggesting nummular or microbial eczema (Figures 1a and 1b).
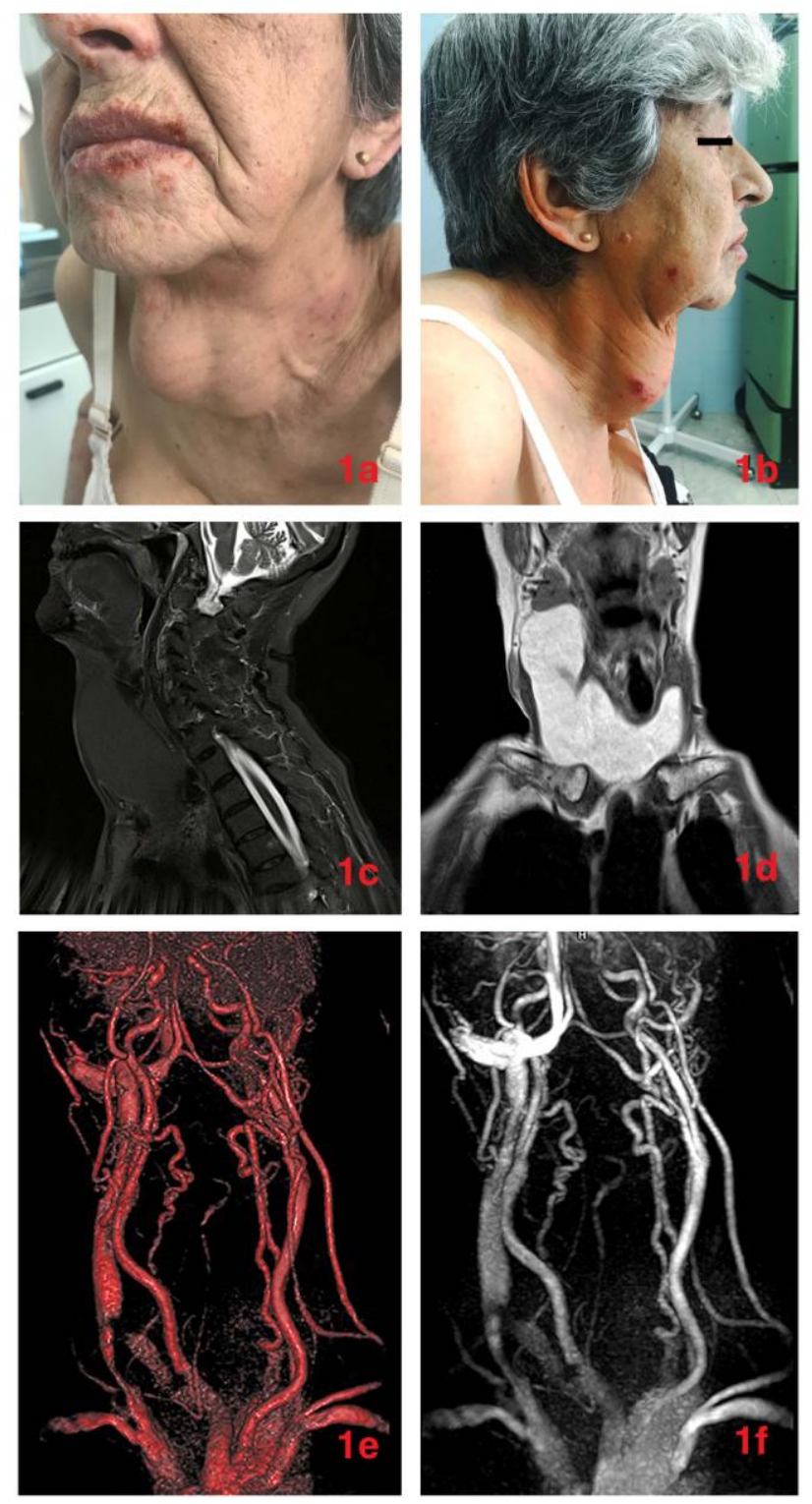

Figure 1: a, b) At the dermatological examination (front and sideways of the neck)-an oval lesion with the soft-elastic constellation. Clinical image of disseminated nummular partially pyodermic patches; $c$, d) Pre-surgical magnetic resonance imaging of the neck confirmed the presence of a lesion of the anterior cervical space. Tumour burdens from horizontal and vertical view; e, f) MRI contrasting blood system in the neck

During the examination, in the neck area, parathyroid was visualised a subcutaneous tumour formation with a relatively soft but also an elastic constellation, painless, consisting of 2 confluent subcutaneous nodules with a total size of 13 to $8 \mathrm{~cm}$ (Figures 1a and 1b). The results of the routine blood tests showed elevated cholesterol levels of 6.6 $\mathrm{mmol} / \mathrm{l}, \mathrm{HDL}-2.25 \mathrm{mmol} / \mathrm{l}, \mathrm{LDL}-3.9 \mathrm{mmol} / \mathrm{l}$. Ultrasound of the thyroid gland revealed a hypoechoic formation with streakiness and rounded adenomatous sections covering the right thyroid. Radiography of the neck area showed moderately arcuate displaced trachea to the left at the C4-C7 level. The cytological result of the ultrasound-controlled aspiration biopsy and subsequent specific lipid stains confirmed a benign lipoma. An MRI study was conducted which identified the presence of a large, subcutaneously located lesion of irregular shape and homogeneous structure, with a well-formed capsule (Figures 1c and 1d). The process penetrated insignificantly in the mediastinum of up to $11.5 \mathrm{~mm}$ caudally from the upper edges of the clavicles (Figure 1c).

Furthermore, there was an increase in the size of the right sublingual, submandibular and parotid glands. As a consequence, a dislocation of the carotid system and the right jugular vein was noted. There was a relative reduction of blood flow in the left sigmoidal sinus and left internal jugular vein but a compensatory collateral venous blood flow in the course of external jugular and submandibular veins to the left, as well as deep cervical veins (Figures 1e and $1 \mathrm{f})$.

\section{Discussion}

Lipomas are benign mesenchymal tumours that usually engage the subcutaneous tissue but may occur in internal organs as well [1]. Each part of the body can be affected, with the anterior neck being one of the most uncommon locations [2]. This localisation requires further investigations to exclude a possible connection to the thyroid gland [2]. Intraglandular tumours of the parotid gland and other glands have been described in the medical literature [10] [11]. In our patient, the cytological data from the fine needle aspiration biopsy showed an origin from the adipose tissue with a benign nature. Imaging techniques (ultrasound diagnosis, X-ray and MRI of the cervical area) excluded a communication with the thyroid. Also, a giant parapharyngeal lipoma extending to the pterygoid region (anterior skull base) could also be excluded [7].

Lipomas are characterised by enlarged but truly benign adipocytes surrounded by a capsule. Some unconventional forms of lipomas, including chondroid lipoma, angiolipoma, pleomorphic / spindle cell lipoma and dysplastic lipoma may also be observed [4] [5] [8] [9]. The so-called dysplastic lipomas do not exert MDM2 gene amplification but are overexpressing p53 and may demonstrate abnormalities of the Rb1 gene as well as the probability of some cases being associated with other tumours such as retinoblastoma [4].

Even rarely, malignant transformation of lipomas is possible [3]. De novo developed liposarcomas should also be considered in a differential diagnostic aspect [3]. Sometimes the distinction between lipoma and sarcoma is extremely 
difficult, but it is of paramount importance, as the therapeutic approach is radically different [5] [8].

Although they are slow-growing and usually painless, as with our patient, in rare cases lipomas can engage and infiltrate muscles, and especially in the cervical area, to induce symptoms that require the necessity of surgical treatment [5] [6]. Adequate preoperative diagnosis is important to assure adequate tumour control as well as optimal functional and cosmetic outcome since delicate structures a close in the neck region.

\section{References}

1. Panse N, Sahasrabudhe P, Chandanwale A, Joshi N. A Rare Case of Horse Shoe Shaped Lipoma of the Upper Extremity. World J Plast Surg. 2013; 2(1): 41-43. PMid:25489503 PMCid:PMC4238334

2. Jain G, Tyagi I, Pant L, Nargotra N. Giant Anterior Neck Lipoma with Bleeding Pressure Ulcer in an Elderly Man: A Rare Entity. World J Plast Surg. 2017; 6(3):365-368. PMid:29218288 PMCid:PMC5714984

3. Casani P, Marchetti M, Dallan I, Cagno C, Berretini S. Liposarcoma of the cervico-nuchal region. Otolaryngol Head Neck Surg. 2005; 133:1-3. https://doi.org/10.1016/j.otohns.2004.09.074 PMid:16213951

4. Michal M, Agaimy A, Contreras A, Svajdler M, Kazakov D, Steiner P, Grossmann P, Martinek P, Hadravsky L, Michalova K Svajdler P, Szep Z, Michal M, Fetsch J. Dysplastic Lipoma: A
Distinctive Atypical Lipomatous Neoplasm With Anisocytosis, Focal Nuclear Atypia, p53 Overexpression, and a Lack of MDM2 Gene Amplification by FISH: A Report of 66 Cases Demonstrating

Occasional Multifocality and a Rare Association With Retinoblastoma. Am J Surg Pathol. 2018 (E-pub ahead).

5. Austin R, Mack G, Townsend C, Lack E. Infiltrating (intramuscular) lipomas and angiolipomas. A clinicopathologic study of six cases. Arch Surg. 1980; 115(3):281-4. https://doi.org/10.1001/archsurg.1980.01380030031007 PMid:7356383

6. Kogure K, Yamazaki M, Tamaki T, Node Y, Morita A. Neck and Occipital Pain Caused by Deep Cervical Intramuscular Lipoma: A Surgical Case. J Nippon Med Sch. 2017; 84(2):96-99. https://doi.org/10.1272/jnms.84.96 PMid:28502967

7. Hakeem A, Hakeem I, Budharapu A, Wani F. Giant Parapharyngeal Space Lipoma Extending to the Pterygoid Region (Anterior Skull Base). J Craniofac Surg. 2018; 29(2):e149-e150. https://doi.org/10.1097/SCS.0000000000004384

8. Katsuyama Y, Shirai T, Terauchi R, Tsuchida S, Mizoshiri N, Mori Y, Kubo T. Chondroid lipoma of the neck: a case report. BMC Res Notes. 2018; 11(1):415. https://doi.org/10.1186/s13104-0183523-2 PMid:29954455 PMCid:PMC6022339

9. Samujh R, Peters N, Chhabra A, Almudeer A. Pleomorphic Lipoma of the Neck in an Infant: A Rare Clinical Entity. J Indian Assoc Pediatr Surg. 2017; 22(3):184-186.

https://doi.org/10.4103/jiaps.JIAPS 1717 PMid:28694582 PMCid:PMC5473311

10. Kim KS, Yang HS. Unusual locations of lipoma: differential diagnosis of head and neck mass. Aust Fam Physician. 2014; 43(12):867-70. PMid:25705737

11. Pennisi M, Conti A, Farina R, Foti PV, Cocuzza G, Boncoraglio A, Costanzo V, Costanzo G. Thyroid adenolipoma: a case report. J Ultrasound. 2018; 21(2):165-168.. https://doi.org/10.1007/s40477017-0270-5 PMid:29374396 